\title{
THE EXPERIENCE OF THE APPLICATION OF A GAMIFIED VIRTUAL LEARNING ENVIRONMENT IN HIGHER EDUCATION
}

\author{
Marcos Mincov Tenório', Rui Pedro Lopes ${ }^{2}$, Lourival Aparecido de Góis ${ }^{1}$, \\ Cristina Mesquita ${ }^{2}$, Guataçara dos Santos Junior ${ }^{1}$ \\ ${ }^{1}$ Universidade Tecnológica Federal do Paraná (BRAZIL) \\ ${ }^{2}$ Instituto Politécnico de Bragança (PORTUGAL)
}

\begin{abstract}
Virtual Learning Environments (VLE) provide a way for students to access and interact with learning experiences and assume the responsibility for their own learning, overcoming passive attitudes of listening and memorizing content. In other words, VLEs should be developed to provide teaching and learning environments that allows students to assume an active role in the development of their own knowledge and to increase their involvement.

This work describes an experience of the application of a gamified VLE for the development of nonpresential teaching and learning activities in the course of Statistics in a Management degree. To assess its impact, a quanti-qualitative methodology was used. Data was collected by four instruments: an online questionnaire with closed questions for students, an online questionnaire with open questions for students, a structured interview with the teacher, and instrumentation of the VLE to collect users' actions on the platform.

Results suggest that both teacher and students consider that it is beneficial to use the VLE because of its ubiquity and flexibility. Both students and the teacher consider that using VLE is beneficial, although the adaptation to gamification elements and concepts is still a challenge. The involvement of the teacher and the articulation between the VLE and the pedagogical approach is of the utmost importance to foster the students' involvement in the teaching-learning process.
\end{abstract}

Keywords: Virtual Learning Environments, Gamification, Statistics, E-Learning.

\section{INTRODUCTION}

Gamification is a relatively new term that suggest the use of game elements and game-design techniques in non-game contexts [1]. Gamification promises to increase the involvement of users in online environments [2]. However, a gamified approach cannot be confused with a serious game or a game development process. It consists of, as suggested before, using game elements and design inside environments to improve positive behaviors and maintain the environment's specific objective, called 'non-game contexts' [2].

Nowadays, several authors report prominent findings when applying gamification in teaching-learning environments and suggest that this can have important contributions on these scenarios [3]-[5]. The positive outcome of this strategy is due to the gap of new trends in teaching-learning environments that promote student's engagement on their process of knowledge construction.

During the teaching-learning process, students' engagement can be improved by using motivational elements such as rewards, points, levels, progression, typical in games. With careful articulation and adoption of (some of) these elements, gamification drives students' attention towards a topic or subject, improving motivation and contributing to use more time and effort in the process [3].

Meanwhile, Virtual Learning Environments (VLE) are increasingly being used to provide access to a learning environment regardless of the place and time, allowing the students to progress according to their agenda and to access the teaching-learning experiences anytime, anywhere. VLE combines Information and Communication Technology with educational scenarios and allows the students to interact with the learning environment through the network [6]. This flexibility can further contribute to the integrating students that, otherwise, would not be able to study. Moreover, they also contribute to stimulate the students' active role and autonomy [7], [8].

However, in spite of the positive outcomes of VLE usage, some researchers realized that some VLE may suffer from low motivational aspects [9], [10]. This justified the development of a gamified virtual 
learning environment approach. An environment that enables students to perform educational activities and appeal to high engagement levels [11].

\section{THE ECLASS PLATFORM}

Virtual Learning Environment aims primarily at increasing the students' involvement and, at the same time, allowing teachers to maintain and evaluate their development and provide immediate feedback [11]. The teachers' role is to manage course content and activities, registering exercises on the courses database that are later used as a part of the activity tests. The students' access the courses' content and perform assessments through activity tests.

Each activity test is a set of exercises randomly extracted from the course database. The students are free to choose any content and difficulty, with unlimited attempts and instant feedback. This creates a 'sandbox game' approach, providing a continued formative assessment. Teachers also receive the results, enabling them to track and guide the students' progress and as well as to extract summative assessment results for grading.

On this scenario, gamification mechanics create a game approach, with gamification elements to drive students' involvement and guide them on the desired sequence. Gamification provides incentives to students in order to maintain them on learning objectives and pathway.

The proposed Virtual Learning Environment, which we identify as eClass, aims primarily at increasing students' involvement and, at the same time, allowing teachers to control and evaluate the student's development and provide effective assessments.

\subsection{Gamification Approach}

To offer a detailed understanding of gamification technique applied inside the VLE, this subsection briefly describes the selected elements and mechanics. Before, we need to acknowledge what contributes to the involvement and guidance of students through adequate learning pathway [11].

An important gamification element is 'Experience Points' (EXP), a numeric value that students collect during all-period of VLE usage (Equation 1).

$$
E X P=\sum_{i=1}^{n} E X P_{i}
$$

EXPi is a result value $[0,100]$ of an activity test $i$, of $n$ total attempts. Before taking an activity test, the students choose two parameters: difficulty (dif) and content $(c)$. Then, EXPi is calculated by equations $2,3,4$ and 5 , according to the chosen parameters.

$$
\begin{aligned}
& j=1 \quad \rightarrow E X P_{i}=\text { performance } \\
& j=2 \rightarrow E X P_{i}=\text { performance } \times 0.6 \\
& j=3 \rightarrow E X P_{i}=\text { performance } \times 0.3 \\
& j \geq 4 \quad \rightarrow \quad E X P_{i}=\text { performance } \times 0.1
\end{aligned}
$$

Here, $j$ is the number of attempts inside a selected content and difficulty parameter. By the equations 2-5 it is possible to understand that the EXPi value is inversely proportional to $j$. This occurs to prevent students from performing activities with parameters (contents and difficulties) that they are not yet prepared. If they do, they lose an opportunity to achieve higher values of EXP.

Another gamification element used is 'Virtual Currency' (eCoin). This currency is collected according to the EXPi values and chosen difficulty (1-3 range) in an activity attempt (Equation 6).

$$
e \text { Coin }=(E X P i / 10) \times d i f
$$

The eCoin is a virtual good that can be traded. This gamification mechanic is used in the eClass by the students to remove a question or answers from an activity test, thus giving them the opportunity to achieve better results. Both elements attempt to drive students in a desired pedagogical track, guiding them to pursuit the difficulties that they are prepared to do. Otherwise, they will have less chances of collecting EXP and eCoins.

Besides EXP and eCoins, there are other elements like progress bars, levels, pathways. These elements are chosen according to their feedback ability and attractive design, but with a simple mechanic behind it. Finally, other gamification mechanics like time constraints and limited resources 
were used inside the VLE activity tests to guide students inside this specific task. These elements and mechanics are shown Fig. 1.

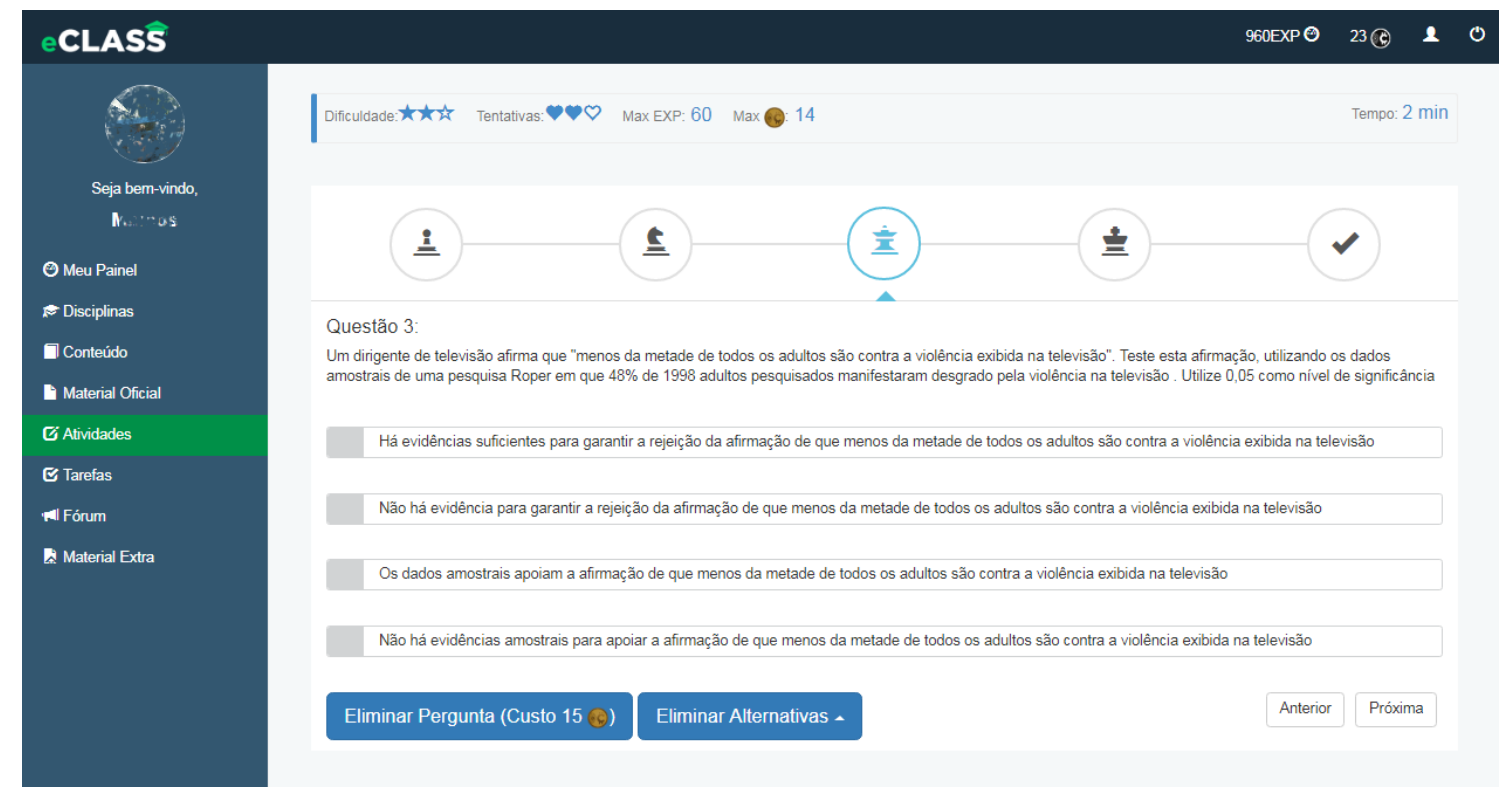

Figure 1. Teaching-learning activity screenshot [11].

\section{METHODOLOGY}

The proposed gamified Virtual Learning Environment (eClass) was applied in an undergraduate class of the Instituto Politécnico de Bragança. In the course of Statistics in a Management degree, 12 students used the proposed software, to perform teaching-learning activities and allowing the teachers to manage the content and the students' progress.

To assess its impact, a quanti-qualitative methodology was used. Data was collected by four instruments: a) an online questionnaire with open questions for students, b) an online questionnaire with closed questions for students, c) and interview with the teacher, and d) the users' actions collected through instrumentation of the VLE.

Students had access for 60 days, performing the designed activities. In total, 175 teaching-learning experiences were created, structured in 11 areas and 3 different difficulty levels. Students were able to do the experiences without any time constraint. The feedback was constant, giving students immediate notion of their success and the teacher a report of the students' progress.

\subsection{Open Questions Questionnaire}

The first instrument was used to get the students' opinion regarding their opinion about the teachinglearning strategies. An open-questions questionnaire was used, allowing the free expression of the participants (Tab. 1).

Table 1. Open questions questionnaire.

\begin{tabular}{c|l}
\hline Study Dimensions & \multicolumn{1}{c}{ Open-Questions } \\
\hline $\begin{array}{c}\text { Methodology / } \\
\text { strategies of } \\
\text { teaching-learning }\end{array}$ & $\begin{array}{l}\text { In your opinion what are the main teaching-learning strategies in higher education? } \\
\text { Would you mind giving an example of methodologies that teachers use in classes? }\end{array}$ \\
\hline $\begin{array}{c}\text { Degree of satisfaction } \\
\text { and motivation with } \\
\text { the pedagogical } \\
\text { methodologies }\end{array}$ & $\begin{array}{l}\text { What kind of methodologies or strategies you consider more important in your own } \\
\text { learning process: The ones where you listen to the teacher or the ones you } \\
\text { participate? } \\
\text { Would you mind giving an example of a class that you liked and another that you } \\
\text { didn't like? Why? } \\
\text { What do you think is more important: to pay attention in class to what the teacher is }\end{array}$ \\
\hline \hline
\end{tabular}




\begin{tabular}{c|l}
\hline \hline & $\begin{array}{l}\text { saying or to discover and discuss the subject with the colleagues? What if they do not } \\
\text { collaborate? } \\
\text { What do you think about being autonomous in the learning process? Do you think } \\
\text { that autonomy is promoted in higher education? } \\
\text { What are your main educational concerns about learning experiences? }\end{array}$ \\
\hline $\begin{array}{c}\text { Statistics } \\
\text { expectations }\end{array}$ & $\begin{array}{l}\text { What do you expect to learn in statistics? } \\
\text { What kind of learning strategy could be used in statistics learning? Why? } \\
\text { learning? }\end{array}$ \\
\hline \hline
\end{tabular}

\subsection{Closed Questions Questionnaire}

The second instrument was used to get the opinion of the students regarding the software quality. A closed questionnaire was used based on System Usability Scale (SUS), a simple ten-item scale where a statement is made and the respondent then indicates the degree of agreement or disagreement with the statement on a 5 point scale [12] (Tab. 2).

Table 2. Closed questions questionnaire.

\begin{tabular}{c|l}
\hline \hline Number & \multicolumn{1}{c}{ Questions } \\
\hline 1 & I think that I would like to use this system frequently. \\
\hline 2 & I found the system unnecessarily complex. \\
\hline 3 & I thought the system was easy to use. \\
\hline 4 & I think that I would need the support of a technical person to be able to use this system. \\
\hline 5 & I found the various functions in this system were well integrated. \\
\hline 6 & I thought there was too much inconsistency in this system. \\
\hline 7 & I would imagine that most people would learn to use this system very quickly. \\
\hline 8 & I found the system very cumbersome to use. \\
\hline 9 & I felt very confident using the system. \\
\hline \hline
\end{tabular}

\subsection{Teacher Semi structured interview}

The third instrument was a guided semi structured interview with the teacher, allowing her free expression. We analyzed if the teacher considers to be positive the use of VLE in the discipline. We investigated three dimensions of the positive outcomes: students' motivation, students' performance, teacher general thoughts (Tab. 3).

Table 3. Teacher interview.

\begin{tabular}{c|l}
\hline \hline Dimensions & \multicolumn{1}{c}{ Questions } \\
\hline Students motivation & $\begin{array}{l}\text { Do you consider that students were motivated by this proposal? } \\
\text { Do you believe that game elements can motivate students to perform activities? }\end{array}$ \\
\hline Students performance & Did you notice any change in the academic performance of students? \\
\hline General thoughts & $\begin{array}{l}\text { What is the advantage to the teacher in using the software? } \\
\text { What is the disadvantage to the teacher in using the software? } \\
\text { Is there anything else to add about using the software in your course? }\end{array}$ \\
\hline \hline
\end{tabular}

\subsection{VLE Collected Data}

Finally, we collect data directly from the VLE by log analysis. Several activities' logs were extracted to identify some behavior inside the software. The extracted data were divided into two dimensions: 
gamification data (earned EXP; earned eCoins; traded eCoins) and usage data (trades performed; number of attempts).

\subsection{Open Questions Questionnaire}

From the content analysis of the preliminary open-questions questionnaire applied to students, four categories emerged: A) teaching-learning methodologies; B) teaching-learning process; C) Statistical learning; D) Games as a teaching-learning strategy.

In the category teaching-learning methodologies, the participants mentioned that the strategies most used by teachers are theoretical classes, practical classes, classes where the slides are used for the transmission of content and the use of software created by the institution. Only one participant mentioned the importance of self-study.

However, the most valued methodologies are those that allow students to participate, those that use daily situations and where teacher / student interaction is observed. The participants mention that excessively theoretical classes are boring, which leads to deconcentration. It is also said that the motivation is a responsibility of the teacher and the way in which he stimulates the students for the subjects and the type of contents.

It is mentioned by one of the participants that the students' interest in some knowledge is related to their performance and motivation in the different curricular units. The greater the interest in the content of the curricular unit, the greater the motivation of the student in the classroom.

In the category teaching-learning process most of the participants consider that the most important thing is to pay attention to what the teacher says. The interaction with colleagues is little valued, considering it an unnecessary element in the context of the classroom. Students seem to understand and prefer teaching-learning strategies that place them always in a passive place, assuming the externality of the motivational process. The teacher is placed by the students in the centrality of the educational process, and the colleagues can serve as support, at a later time, after the class. They considered that classes are to be listened to.

Regarding the autonomy that should be granted to students in the teaching-learning process respondents consider that this may be a positive aspect, but the teacher's action is always important. One of the participants even mentions that if autonomy is "too strongly promoted (...) is not at all positive. Interaction with the teacher is necessary. The role [of teachers] is to transmit their knowledge to us the best they can. Nowadays everything is on the Internet, but the experience and interactive ability that a teacher should have is undoubtedly very necessary in student learning".

Another participant considered that autonomy is a relationship build and shared between teacher and student. Learning is built on a continuous and shared process that allows the student to become more and more autonomous.

Regarding the category statistical learning, one of the saliencies of the questionnaires is related to the fact that this should be adapted to the requirements of each programme/profession. There is a relationship between the professional need to use statistics and the depth that this curricular unit should have. For example, Management students consider that it is "very important to know how to interpret the numbers". However, students who attend the Civil Engineering programme consider that it should focus only on basic knowledge, stating that "the contents should not be equal for all programmes", considering "the number of students who fail the statistics course is worrying".

Participants reveal that more time was needed, classes with more exercise and a "more practical application to the world of management". Other students suggest using APP "type [game] the whowants-to-be-millionaire to learn in a fun way."

Related to the games as a teaching-learning strategy category, not all participants reveal that they like games. Those who claim they do like games refers to the games of chance, adventure, action and strategy. Those who like to play reveal different motivations for the games, winning and "discovery, looking for a pattern to solve a certain situation and ways to resolve logistical issues of conflict and power to create alliances."

Most of the participants consider that the game allows better learning, since they can put the player (student) in front of everyday situations and they pose interesting challenges. 
However, one of the participants reveals that games can be considered "a form of distraction, but never a way of life". Most opinions do not reflect on the advantages and disadvantages of using games as a learning support.

Emerges, from the analysis of the questionnaires, that the participants consider relevant their participation in the teaching-learning process, valuing the teacher as a means for their learning. Many consider that games can be a relevant strategy in the learning-teaching process, as long as they focus on solving everyday situations and problems. They consider that the teaching of statistics should be adapted to each programme and that the use of Quizz games could be an added value in their learning.

\subsection{Closed Questions Questionnaire}

The System Usability Scale (SUS) questionnaire allows student's feedback on usability and was applied after the students' used the eClass. This approach aims to collect their first impression of the system. The SUS final result is a weighted value that suggest the system's ease of use (Tab. 4).

Table 4. SUS questionnaire result.

\begin{tabular}{l|c|c}
\hline \multicolumn{1}{c|}{ Questions } & $\begin{array}{c}\text { Average } \\
\text { Value }\end{array}$ & $\begin{array}{c}\text { Weighted } \\
\text { Value }\end{array}$ \\
\hline 1. I think that I would like to use this system frequently. & 3.75 & 2.75 \\
\hline 2. I found the system unnecessarily complex. & 1.75 & 3.25 \\
\hline 3. I thought the system was easy to use. & 4.5 & 3.5 \\
\hline $\begin{array}{l}\text { 4. I think that I would need the support of a technical person to be able to use } \\
\text { this system. }\end{array}$ & 1.75 & 3.25 \\
\hline 5. I found the various functions in this system were well integrated. & 3.75 & 2.75 \\
\hline 6. I thought there was too much inconsistency in this system. & 2.25 & 2.75 \\
\hline 7. I would imagine that most people would learn to use this system very quickly. & 4.5 & 3.5 \\
\hline 8. I found the system very cumbersome to use. & 1.25 & 3.75 \\
\hline 9. I felt very confident using the system. & 4.25 & 3.25 \\
\hline 10. I needed to learn a lot of things before I could get going with this system. & 2 & 3 \\
\hline
\end{tabular}

According to the scale, a product's usability is acceptable for values higher than $55 \%$. The results show a $79.37 \%$ value, suggesting a high score according to the ease of use. In other words, students have the perception that the software is easy and friendly to use. They found little or no difficulties exploring and using the available tools and sections.

\subsection{Teacher Interview}

From the teacher interview, four categories emerge: A) Students' motivation; B) Games as educational tool; C) Advantages for the teacher; D) Disadvantages for the teacher.

In the category students' motivation, the teacher considers that the gamification approach motivated the students for learning. However, she considers that this motivation wasn't so effective considering the characteristics of the students, since this was an after-work class, where students are not so available for this kind of teaching-learning strategies. She believes that this strategy would be more successful in classes with younger students, that like to play games and with spare time to perform extra-class activities.

According to the teacher, students had difficulty understanding the usability of the game, not understanding the role of the eCoin or its advantage in the process. Students only tried to understand and take profit of all the concepts in the end of the process, as a means to get better grades. 
The teacher also considers that students found a way to cheat, by "performing print-screens of the questions to retain them and think about them afterwards". In this sense, she refers that the students used the platform not because of its characteristics and advantages, but to get better grades.

In the category games as educational tool, the teacher did not realize if the software contributed to increase the performance and motivation of students, since they did not get involved sufficiently with the process. She considers that this kind of games will be successful if associated to the grade. She considers that the software can be improved with a larger number of questions so that students are not able to cheat.

As advantages, the teacher refers the involvement of the students with the content. As disadvantages, she considers the task of creating and inserting a large number of questions very demanding and time-consuming.

\subsection{VLE Collected Data}

Here we gather the system's results regarding user's actions and results inside eClass (Tab. 5).

Table 5. System results.

\begin{tabular}{c|c|c|c|c|c}
\hline \multirow{2}{*}{ Students ID } & \multicolumn{3}{|c|}{ Gamification Data } & \multicolumn{2}{c}{ Usage Data } \\
\cline { 2 - 6 } & $\begin{array}{c}\text { Earned } \\
\text { EXP }\end{array}$ & $\begin{array}{c}\text { Earned } \\
\text { eCoins }\end{array}$ & $\begin{array}{c}\text { Traded } \\
\text { eCoins }\end{array}$ & $\begin{array}{c}\text { Trades } \\
\text { Performed }\end{array}$ & $\begin{array}{c}\text { Activities } \\
\text { Attempts }\end{array}$ \\
\hline 3 & 3888 & 522 & 480 & 67 & 314 \\
\hline 6 & 3574 & 649 & 530 & 53 & 117 \\
\hline 2 & 2688 & 475 & 22 & 4 & 93 \\
\hline 9 & 2611 & 416 & 389 & 39 & 92 \\
\hline 12 & 1421 & 174 & 45 & 6 & 36 \\
\hline 10 & 1180 & 148 & 86 & 13 & 63 \\
\hline 5 & 1083 & 142 & 68 & 10 & 43 \\
\hline 1 & 799 & 112 & 0 & 0 & 35 \\
\hline 4 & 336 & 33 & 0 & 0 & 8 \\
\hline 7 & 98 & 10 & 0 & 0 & 2 \\
\hline 8 & 0 & 0 & 0 & 0 & 0 \\
\hline 11 & 0 & 0 & 0 & 0 & 0 \\
\hline Standart Deviation & 1330.27 & 219.75 & 195.46 & 22.49 & 83.57 \\
\hline \hline
\end{tabular}

We analyze the results in two perspectives: gamification data and usage data. From the gamification data perspective, it is possible to understand that the Earned EXP reflect students' engagement on the software mostly because it correlates with all other collected variables. Additionally, the eCoin was heavily used by some students to perform trades (e. g. student 3, 6 and 9) and they spend on average $40 \%$ of their funds. However, there are students that have some difficulty accepting spending their eCoins, although keeping a significant value (e. g. student 1 and 2). This may be an indication that they did not find an insurmountable difficulty or that they just like to save for the future. Overall, we understand that EXP element is proven to be an important indicator of the students' engagement, and eCoin a mechanism that may reflect the student's behavior when facing some difficulties.

From the usage data perspective, we access activities attempt as the primary indicator of the software usage. Despite the software allows students to perform unlimited activities, the teacher registered 11 content sections (or study units) with 3 difficulties each. Then, as a minimum, students are required to perform 33 activity tests. Based on this assumption, 4 students did not manage to complete the minimum required by the teacher and 2 of them did not use the software to register their tests. 
However, most of the students completed the required activities and 2 of them (student 3 and 6) performed a considerable number of activities reflected on their final results.

\section{CONCLUSIONS}

This study describes the development and application of a Virtual Learning Environment enriched with Gamification elements to foster students' autonomy and motivation. This online platform allows teachers to manage the content and the progress of students and allows students to constantly be aware of their successes and failures, with alternatives to constantly progressing through the course, anytime, anywhere.

In this study, the platform was applied in a Statistics course, with students from the degrees in Management and Civil Engineering. Students are mostly working students with specific characteristics for learning.

They were not very motivated to learning with gamification and with alternative methodologies beyond the traditional methods, because they wanted to get the most of the contact with the teacher, since they do not have spare time to study at home. They see the teacher as a specialist and experiences lecturer, that could help them through the path of learning. However, they also believed that learning with games could be an important strategy for students with spare time.

It is clear that it is of the utmost importance that the teacher demonstrates a strong knowledge of the strategy so that students are involved in the process. This process should be understood as a challenge for students. Beyond a mere game of learning, it should be structured as a mean of knowledge organization and simulation, with adaptive difficulties challenges, stimulating students to think about different possibilities, act on the error and overcome obstacles.

Before clarifying the students about the process, it is important to reflect with the teacher and to help him be aware of the value of the process as an alternative way to motivate students for learning and to stimulate their autonomy for self-study and knowledge discovery.

\section{REFERENCES}

[1] S. Deterding, D. Dixon, R. Khaled, e L. Nacke, "From Game Design Elements to Gamefulness: Defining 'Gamification'”, in Proceedings of the 15th International Academic MindTrek Conference: Envisioning Future Media Environments, New York, NY, USA, 2011, p. 9-15.

[2] S. Deterding, R. Khaled, L. Nacke, e D. Dixon, "Gamification: Toward a definition", in CHI 2011 Gamification Workshop Proceedings, 2011, p. 12-15.

[3] L. Ding, C. Kim, e M. Orey, "Studies of student engagement in gamified online discussions", Comput. Educ., vol. 115, p. 126-142, dez. 2017.

[4] K. Seaborn e D. I. Fels, "Gamification in theory and action: A survey", Int. J. Hum.-Comput. Stud., vol. 74, p. 14-31, fev. 2015.

[5] U. Jayasinghe e A. Dharmaratne, "Game based learning vs. gamification from the higher education students' perspective", in 2013 IEEE International Conference on Teaching, Assessment and Learning for Engineering (TALE), 2013, p. 683-688.

[6] W. Sun e W. Zhang, "The Research of Collaborative E-learning System towards Knowledge Management", 2008, p. 354-357.

[7] M. Prensky, "Our Brains Extended”, Technol.-Rich Learn., vol. 70, n 6, p. 22-27, mar. 2013.

[8] C. Batanero, G. Burrill, e C. Reading, Teaching Statistics in School Mathematics-Challenges for Teaching and Teacher Education: A Joint ICMIIIASE Study: The 18th ICMI Study. Springer Science \& Business Media, 2011.

[9] M. A. Santana, B. F. dos S. Neto, e E. de B. Costa, "Avaliando o Uso das Ferramentas Educacionais no Ambiente Virtual de Aprendizagem Moodle”, An. Simpósio Bras. Informática Na Educ., vol. 25, $\mathrm{n}^{\circ}$ 1, p. 278-287, 2014.

[10] L. Valente, P. Moreira, e P. Dias, "Moodle: Moda, Mania ou Inovação na Formação?", in Moodle: estratégias pedagógicas e estudo de caso, Slavador: Universidade do Estado da Bahia, 2009, p. 35-54. 
[11] M. M. Tenório, R. P. Lopes, L. A. de Góis, e G. dos S. Junior, "A Gamified Virtual Learning Environment for Statistics Learning", in INTED2018 Proceedings, Valencia, Spain, 2018, p. 6248-6257.

[12] J. Brooke, "System usability scale (SUS): A quick-and-dirty method of system evaluation user information", in Digital Equipment Co Ltd, UK, 1986. 